\title{
Nanotheranostics
}

2018; 2(4): 347-359. doi: 10.7150/ntno.26119

\section{Hyaluronic Acid-Based Optical Probe for the Diagnosis of Human Osteoarthritic Cartilage}

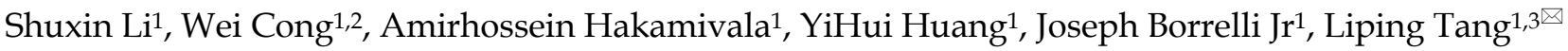 \\ 1. Department of Bioengineering, University of Texas at Arlington, Arlington, TX 76019, USA \\ 2. Department of Oral Anatomy, College of Stomatology, Dalian Medical University, Dalian, Liaoning, 116044, China \\ 3. Department of Biomedical Science and Environmental Biology, Kaohsiung Medical University, Kaohsiung 807, Taiwan \\ $\triangle$ Corresponding author: Department of Bioengineering, University of Texas at Arlington, P.O. Box 19138, Arlington, TX 76019-0138, USA. Tel.: +1 817 272 6075; \\ fax: +1 817272 2251. E-mail address: ltang@uta.edu. \\ (c) Ivyspring International Publisher. This is an open access article distributed under the terms of the Creative Commons Attribution (CC BY-NC) license \\ (https://creativecommons.org/licenses/by-nc/4.0/). See http://ivyspring.com/terms for full terms and conditions.
}

Received: 2018.03.18; Accepted: 2018.07.15; Published: 2018.07.26

\begin{abstract}
Osteoarthritis is typically caused by cartilage injury, followed by localized inflammatory responses and tissue deterioration. Early treatment of osteoarthritis is often impossible due to the lack of diagnostic options. Recent studies have supported that different imaging probes can be used for arthritis detection in mice. However, none of these diagnostic tools have been tested on human articular cartilage. To fill this gap, an optical imaging probe was developed to target activated macrophages and the accumulation of imaging probes on tissue was used to assess the severity of human osteoarthritis.

Methods: The probe was fabricated using hyaluronic acid $(\mathrm{HA})$ particles conjugated with near-infrared dye and folic acid (FA). The ability of the FA-HA probes to detect activated macrophages and quantify cartilage injury was evaluated using a cell culture model in vitro and human osteoarthritic cartilage explants ex vivo.

Results: Our cell study results supported that the FA-HA probes are cell compatible (up to $0.5 \mathrm{mg} / \mathrm{mL}$ ) and can detect activated macrophages in 30 minutes. Using human articular cartilage, we verified the existence of activated macrophages on osteoarthritic cartilage with highly up-regulated expression of folate receptors $(\sim 13$ folds by comparison with healthy control). In addition, we found that FA-HA probes had higher binding amounts ( $\sim 3$ folds) to osteoarthritic tissue than healthy ones. Histological analyses confirmed that there was a strong linear relationship $(R=0.933)$ between the fluorescent intensity of tissue-associated probe and the extent of folate receptors on osteoarthritic cartilage. Finally, the co-localization of the imaging probe, folate receptors and cartilage degeneration on the tissue sections indicated the extraordinary accuracy and efficiency of this osteoarthritis diagnostic probe.
\end{abstract}

Conclusions: Our results support the probe as an effective diagnostic tool to detect the area and severity of osteoarthritic human articular cartilage.

Key words: osteoarthritis; diagnosis; optical probes; hyaluronic acid; folate receptor; human explant.

\section{Introduction}

Osteoarthritis has become a major cause of disability in the United States responsible for a tremendous sociological and economic burden [1, 2]. Early diagnosis and treatment of osteoarthritis is believed to delay disease progression and improve the patient outcome [3]. According to the Arthritis Foundation, osteoarthritis may be diagnosed by a physical examination, followed by confirmation with joint aspiration, $\mathrm{X}$-ray and Magnetic Resonance Imaging (MRI) [4-6]. Unfortunately, joint aspiration and X-ray imaging are unreliable and cannot be used to detect localized cartilage injury before any structural damage emerges [7, 8]. MRI is comparatively sensitive, valid and reproducible for assessing whole-joint structures including cartilage degeneration, subchondral bone marrow lesions, joint effusion and synovitis [9]. However, MRI is unable to detect localized cartilage tissue deterioration which is often associated with the early onset of osteoarthritis [10]. Therefore, there is a need for the development of new methods to assess localized cartilage damage of osteoarthritis. 
Increasing evidence supports that synovial macrophages play an important role in the progression of osteoarthritis [11-13]. Firstly, the accumulation of macrophages at the synovial lining and cartilage surfaces is the first symptom of osteoarthritis [11]. Secondly, macrophages are the most prevalent cells that infiltrate in a human osteoarthritic joint, accounting for $65 \%$ of all infiltrating cells [14]. Thirdly, a recent study has shown that activated synovial macrophages enhance osteophyte formation, fibrosis and many signs of osteoarthritis [15]. Fourthly, inflammatory cytokines released by activated macrophages, such as TNF- $\alpha$ and IL-1 $\beta$, have been shown to promote the inflammatory and destructive responses in osteoarthritis [12]. Lastly, the critical role of macrophages in osteoarthritis progression is confirmed in a study that shows that the depletion of synovial macrophages results in a significant reduction of osteophyte and fibrosis formation in a murine osteoarthritis model [15]. These results suggest that the detection of activated macrophages is a reliable indicator for assessing the severity and location of osteoarthritis.

The folate receptor (FR) is a family of glycosyl phosphatidylinositol-anchored proteins and has high affinity for FA [16]. Beta form of FR (FR $\beta)$ is specifically expressed on activated macrophages in inflamed joints and has been used as a target for drug delivery $[17,18]$ based on several unique characteristics of the FR. Firstly, expression of FR can only be found on activated macrophages but no other blood cells such as lymphocytes, granulocytes or erythrocytes [19]. Secondly, increased amount of FR is present on activated macrophages in the inflammatory environment but not on quiescent resident macrophages [20]. Finally, folate targeting near infrared probes were found to able to assess the disease progression of LPS induced arthritis mice model by quantifying the extent of active macrophage accumulation in the joints [21]. These results support that folate probes can be developed to detect the presence of activated macrophages on osteoarthritic cartilage via FR-folate interaction.

Several imaging modalities have been investigated on their ability to detect activated macrophages during the progression of rheumatoid arthritis and osteoarthritis. Using single-photonemission computed tomography, a study demonstrated that a diethylene triaminepenta acetic acid (DTPA)-folate probe can be fabricated to monitor the macrophage accumulation in joint tissue of rat osteoarthritis models [22]. Folate-conjugated $99 \mathrm{mTc}$ chelator was also studied to monitor macrophage recruitment using gamma scintigraphy in a rat RA model [23]. Lastly, a formyl peptide receptor 1-targeting peptide probe cFLFLF-PEG-64 $\mathrm{Cu}$ was investigated for its ability to detect activated macrophages in an induced osteoarthritis rat model via positron emission tomography imaging [13]. While these nuclear medicine methods can detect the accumulation of activated macrophages at the site of arthritis, the risk of radiation exposure limits their use for routine osteoarthritis diagnosis.

To overcome this limitation, other optical imaging methods have been investigated for arthritis diagnosis. For example, a FR-targeting near infrared (NIR) probe was developed to detect activated macrophage recruitment in mice with induced rheumatoid arthritis [21]. Another study has shown that NIR dye (Cy5.5 fluorochrome)-conjugated anti-macrophage antibody (anti-F4/80 antibody) can be used to visualize the presence of a higher number of macrophages at a joint with induced osteoarthritis in mice [24]. Despite all these observations, none of these probes have been evaluated on their capability to diagnose human osteoarthritic cartilage tissue in human, which was the focus of this investigation.

In this study, we fabricated FR-targeting probes by conjugating NIR dye and folic acid onto hyaluronic acid (HA) particles. HA, a natural polymer with inherently biocompatible and biodegradable properties, has been widely used as a drug carrier [25, 26] and imaging probe [27]. The physical, chemical and cellular compatibility of the probes was characterized. The ability of the FA-HA probes to detect and quantify the number of activated macrophages was investigated in vitro. Finally, using discarded human cartilage tissue, we determined the effectiveness of FA-HA probes for identifying the area of osteoarthritic tissue and assessing the extent of osteoarthritic degeneration in human osteoarthritic explants.

\section{Materials and methods}

\subsection{Materials}

HA (sodium salt, 700KDa) was obtained from Lifecore Biomedical (Chaska, MN). Divinyl sulfone (DVS, 97\%), 1-heptanol (98\%) and folic acid (FA, $\geq 97 \%$ ) were obtained from Sigma-Aldrich (St. Louis, MO). Dioctyl sulfosuccinate sodium salt (AOT, 96\%) and isooctane (99\%) were obtained from Fisher Scientific (Hampton, $\mathrm{NH}$ ). Polyethylene glycol $\left(\mathrm{NH}_{2}\right)_{2}$ $(\mathrm{HCl}$ salt, $5000 \mathrm{Da})$ was purchased from Jenkem Technology (Beijing, China). N-Hydroxysuccinimide (NHS) and 1-Ethyl-3-(3-dimethylaminopropyl) carbodiimide were obtained from Thermo Scientific (Rockford, IL). CF647A amine dye was purchased from Biotium, Inc. (Fremont, CA). 


\subsection{Fabrication of FA-conjugating HA probes}

HA particles were synthesized via a water-in-oil microemulsion process as described earlier with minor revisions [28]. Briefly, $3 \mathrm{~mL}$ of $\mathrm{HA}$ aqueous solution (1.5wt \% in $0.2 \mathrm{M} \mathrm{NaOH})$ was added dropwise into an oil phase solution composed of $50 \mathrm{~mL}$ of isooctane, AOT (0.2M) and 1-heptanol $(0.04 \mathrm{M})$ under homogenization at 28,000 rpm (OMNI GLH homogenizer, OMNI international, GA). Divinyl sulfone $(0.015 \mathrm{M})$ was added dropwise into the polymer solution and homogenized at $28,000 \mathrm{rpm}$ for 5 minutes. The reaction then proceeded under vigorous stirring $(2,200 \mathrm{rpm})$ at ambient temperature for 1 hour. Following the addition of $3 \mathrm{~mL}$ of hydrochloric acid $(0.2 \mathrm{M})$ to stop the reaction, the HA particles were collected by precipitation in $80 \mathrm{~mL}$ of acetone and sequentially washed with acetone, ethanol and water. After removal of large (micron-sized) particles via centrifugation $2 \times$ at $6 \times \mathrm{g}$ for 10 minutes, nano-sized particles were collected by centrifugation at $805 \times \mathrm{g}$ for 10 minutes, and the collected nanoparticles were lyophilized and stored at $4^{\circ} \mathrm{C}$ for further use.

HA particles were conjugated with fluorescent dye as described previously [29]. Briefly, HA particles $(50 \mathrm{mg} / \mathrm{mL}$, PBS $\mathrm{pH}=6.0)$ were incubated with EDC $(0.66 \mathrm{M})$ and NHS $(0.66 \mathrm{M})$ at room temperature for 24 hours. The activated HA particles were collected by centrifugation at $805 \mathrm{xg}$ for 10 minutes. The activated HA particles were dispersed in PBS $(\mathrm{pH}=7.2)$ containing CF647A amine dye $(1.2 \mathrm{mM})$ and allowed to react for 24 hours in dark. CF647A-labeled HA particles were purified via the centrifuge. Absorptive and fluorescent spectra of the CF647A-labeled HA particles were measured using an ultraviolet-visible spectrophotometer (Lambda 19 Spectrometer, Perkin Elmer, MA) and an Infinite M200 microplate reader (Tecan, San Jose, CA), respectively.

Some of the CF647A-labeled HA particles were further conjugated with FA to prepare FA receptor-targeting HA (FA-HA) probes. First, FA was modified with PEG $\left(\mathrm{NH}_{2}\right)_{2}$ to introduce an amine group into FA [30]. Namely, FA $(2.8 \mathrm{mM})$ was activated by its overnight incubation in a solution of dimethyl sulfoxide (DMSO) containing EDC (4.2mM) and NHS $(4.2 \mathrm{mM})$ at room temperature; subsequently, PEG $\left(\mathrm{NH}_{2}\right)_{2}(2.8 \mathrm{mM})$ was incubated with the activated FA solution for 24 hours at room temperature in a dark setting to introduce a free amine group into the FA (FA-PEG-NH ${ }_{2}$. FA-PEG-NH $\mathrm{N}_{2}$ was then purified with exhaustive dialysis (molecular cutoff: $2 \mathrm{kDa}$ ) against DMSO and subsequently against water. The FA-PEG-NH $\mathrm{NH}_{2}$ was lyophilized and stored at $4{ }^{\circ} \mathrm{C}$ for further use. To conjugate FA onto CF647A-labeled HA particles, 10 mg of CF647A-labeled HA particles, $6.6 \mathrm{mM}$ of FA-PEG-NH $\mathrm{N}_{2}$ and $66 \mathrm{mM}$ of EDC were dispersed in PBS ( $\mathrm{pH}=4.5)$. After stirring overnight at room temperature, the FA-conjugated CF647A-labeled HA particles (FA-HA probes) were collected via centrifugation at $9,838 \times \mathrm{g}$. The FA-HA probes were washed 3X with DI water, lyophilized and stored under dark conditions for future use.

\subsection{Characterization of FA-conjugated HA probes}

Particle size and particle size distribution were analyzed at a particle concentration of $0.33 \mathrm{mg} / \mathrm{mL}$ using a Photon Correlation Spectrometer and a ZetaPALS Particle Sizing software (ZetaPALS, Brookhaven Instruments Co., Holtsville, NY, USA). The morphology of the probes was observed by using a scanning electron microscope (Hitachi S-4800 II FE SEM, operating voltage $15 \mathrm{kV}$ ).

HA particles were firstly labeled with CF647 before FA conjugation. The conjugation efficiency of CF647A dye was determined based on an established method and equation: Conjugation efficiency = $\left(M_{0}-M_{1}\right) / M_{\mathrm{NP}} \times 100 \%$, where $M_{0}$ is the mass of initial input dye, $M_{1}$ is the mass of unconjugated dye and $M_{\mathrm{NP}}$ is the mass of the HA particles. [31] $M_{1}=$ (volume $\times$ absorbance at $648 \mathrm{~nm} \times$ molecular weight of dye) / (path length $\times$ extinction coefficient of dye at $648 \mathrm{~nm}$ ) [32]. All experimental data is collected in PBS $(\mathrm{pH}=7.4)$. The absorbance (at $648 \mathrm{~nm})$ was measured with a UV/VIS spectrophotometer (Beckman DU-640, Beckman Coulter, TX).

To determine the optical properties of the CF647A-labeled HA particles, $200 \mu \mathrm{L}$ of the probes in PBS $(\mathrm{pH}=7.4)(1 \mathrm{mg} / \mathrm{mL})$ was placed in a 96-well plate and fluorescence spectra were recorded using a SpectraMax Gemini XPS microplate reader (Molecular Devices, Sunnyvale, CA) [33].

To determine the FA conjugation efficacy on the probes, FTIR spectra of FA-HA probes were determined using a Nicolet 6700 FT-IR spectrometer (Thermo Nicolet Corp., Madison, WI) at a resolution of $8 \mathrm{~cm}^{-1}$ with a scan width of $4000-400 \mathrm{~cm}^{-1}$. Conjugation efficiency of FA on probes (FA-PEG mass per milligram of the dried probes) was quantified based on the measurement of FA absorbance at 362nm as described previously [34].

\subsection{Cytotoxicity assay of FA-HA probes}

Cytotoxicity of the probes were evaluated using human chondrocytes (ATCC, Manassas, Virginia) as described earlier [35]. Briefly, cells were seeded in a 96-well plate at a density of $8 \times 10^{3}$ cells/well and incubated in chondrocyte medium (ATCC, Manassas, VA), which was supplemented with $10 \%$ fetal bovine 
serum (FBS) and 1\% penicillin-streptomycin, for 24 hours in an incubator set at $5 \% \mathrm{CO}_{2}$ and $37^{\circ} \mathrm{C}$. The seeded cells were incubated with different concentrations of probe for 72 hours. The adherent cells were washed $3 \mathrm{X}$ with PBS $(\mathrm{pH}=7.4)$ and then incubated with $100 \mu \mathrm{L}$ of media containing $10 \mu \mathrm{L}$ of AlamarBlue $^{\circledR}$ Cell Viability Reagent (Sigma-Aldrich) for 4 hours. A microplate reader (infinite 200, Tecan, Switzerland) was used to record the fluorescent intensities at an excitation of $540 \mathrm{~nm}$ and an emission of $590 \mathrm{~nm}$. Cell viability was determined by the ratio of the fluorescent intensity of experimental group to the fluorescent intensity of control group (no probes added) $\times 100 \%$ [34].

\subsection{In vitro macrophage targeting}

Studies were carried out to illustrate the probes' ability to target activated macrophages using activated THP-1 cells, as described previously [34]. Briefly, human THP-1 monocytic cells (ATCC, 1.5 $\times 10^{4}$ cells/mL/well in RPMI 1640) were incubated with phorbol 12-myristate 13-acetate (PMA, R\&D system) (162 nM PMA for 48 hours) to produce activated macrophages [29]. FA-HA-CF647 probes (final concentration $0.5 \mathrm{mg} / \mathrm{mL}$ ) were then added into activated and naive THP-1 cells for 15 and 30 minutes. To determine the role of the probe's FA on macrophage targeting, a similar in vitro study was carried out, which entailed the incubation of activated THP-1 cells with an excess amount of FA $(18 \mu \mathrm{M})$ for 20 minutes prior to the supplement of FA-HA probes (final concentration $0.5 \mathrm{mg} / \mathrm{mL}$ ) or $\mathrm{HA}$ control particles. At the end of the study, macrophages were washed with fresh media 5X and cell-associated fluorescent intensity in each well was read with a microplate reader. In addition, confocal laser scanning microscopy certified the location of targeted probes on activated THP-1 cells. Specifically, activated THP-1 cells were incubated with either FA-HA probes $(0.1 \mathrm{mg} / \mathrm{mL}$ ) or RPMI 1640 medium (as control) for 4 hours in $37^{\circ} \mathrm{C}$. Cells were washed with PBS $(\mathrm{pH}=7.4)$ three times and then stained with DAPI for three minutes. Thus, the interaction between live cells and probes could be visualized with different laser channels using confocal laser scanning microscopy (Leica TCS SP8 SMD, Leica, Buffalo Grove, IL, USA) at different channels: DAPI channel (Excitation: 400nm, Emission: 470nm, Exposure time: 200ms), Cy5 channel (Excitation: 647nm, Emission: 670nm, Exposure time: $800 \mathrm{~ms}$ ) and White light channel (Exposure time: $100 \mathrm{~ms})$.

Murine Raw 264.7 macrophage (ATCC, Manassas, VA) was the model cell used to assess the effectiveness of FA-HA probes in targeting inflammatory cells. Raw 264.7 macrophages were cultured in folate-free RPMI media containing $10 \%$ FBS at $37^{\circ} \mathrm{C}$ until reaching $75 \%$ confluence. To up-regulate cell surface FR expression, cultured murine macrophages were activated by supplementing $1.0 \mu \mathrm{g} / \mathrm{mL}$ lipopolysaccharide (LPS) (from E. coli, Sigma, St. Louis, MO) for 4 h, as shown in previous publications [36]. After LPS incubation, cells were washed $2 X$ with RPMI to remove non-adherent cells. FA-HA probes (final concentration $0.5 \mathrm{mg} / \mathrm{mL}$ in RPMI) and NIR-labeled control HA particles were co-cultured with different numbers of activated macrophages $(12,500,25,000,50,000$, and 100,000). After a 30-minute culture period, macrophages were washed with PBS ( $\mathrm{pH}=7.4)$ buffer three times to remove free particles/probes. The extent of targeting efficiency was then quantified by measuring the fluorescent intensity at a $630 \mathrm{~nm}$ excitation wavelength and $690 \mathrm{~nm}$ emission wavelength using a microplate reader.

\subsection{Ex vivo targeting of human arthritic cartilage explant}

To assess the ability of FA-HA probes to target OA cartilage tissue, human articular cartilage was obtained from the discarded tissue of anonymous patients $(\mathrm{N}=4)$ undergoing total knee replacement and was stored at sterile saline at $4{ }^{\circ} \mathrm{C}$ for up for 24 hours prior to the experiments. As supported by previous publications [37] and our preliminary studies, the cartilage tissue used in the investigation possessed the histological characteristics and FA-HA probe affinity resembling freshly isolated cartilage samples. Explants were isolated from the weight bearing area in lateral femoral condyles with different severities of osteoarthritis and dissected into the mean size in $\mathrm{mm}: 20.0 \pm 3.3(\mathrm{~L}) \times 13.4 \pm 2.9(\mathrm{~W})$. In addition, explants isolated from non-weight bearing area without apparent osteoarthritis injury was used as healthy controls. The explants were washed gently with sterile saline and then immersed in a 6-well plate containing $3 \mathrm{~mL}$ of saline. Different concentrations (final concentrations, $100 \mu \mathrm{g} / \mathrm{mL}$ and $20 \mu \mathrm{g} / \mathrm{mL}$ ) of FA-HA probes and HA control were added into the well plate which was then placed on a constant shaker in a dark setting. Explants in the plate were imaged at various time points (30, 45, 75, 105 and 135 minutes) using a custom-made fluorescent imaging system, and the collected images were processed as described in our previous publication [38]. Data was plotted in terms of the mean intensity of Region of Interest (ROI) over time.

\subsection{Histological analysis}

After imaging, the explants were embedded in an OCT compound and then sliced into 5- $\mu \mathrm{m}$ sections. 
The sections were fixed in iced acetone $\left(-20^{\circ} \mathrm{C}\right)$ for 5 minutes prior to histological staining. For double staining of FR and macrophages (CD68), the sections were incubated with FR antibody (1:50, Santa Cruz Biotechnology, Santa Cruz, CA, USA) and anti-CD68 antibody (1:80, Abcam, Cambridge, MA, USA) overnight at $4^{\circ} \mathrm{C}$, followed by Alexa Fluor 594-conjugated anti-mouse IgG antibody (1:120, Abcam, Cambridge, MA, USA) and Alexa Fluor 488-conjugated anti-rabbit IgG antibody (1:120, Abcam, Cambridge, MA, USA) incubation for 1 hour at room temperature. A negative control was simultaneously generated by carrying out identical histological staining without the use of primary antibody. To reduce background staining caused by endogenous peroxidase activity and non-specific binding, all section staining was blocked with $3 \%$ hydrogen peroxide (10 minutes) and $5 \%$ purified goat serum (10 minutes), respectively. For the immunohistochemistry (IHC) staining, the sections were incubated with FR antibody (1:50, Santa Cruz Biotechnology, Santa Cruz, CA, USA) overnight at $4^{\circ} \mathrm{C}$ and followed by HRP-conjugated anti-mouse IgG antibody (1:500, Abcam, Cambridge, MA, USA) incubation for 1 hour at room temperature. Diaminobenzidine (DAB, sigma, MO, USA) was used as a chromogen for color development and methyl green was used as counterstain. FR scores were calculated to quantify the degree of FR expression, based on a published study [39]. Briefly, A (number of positive cells) and $\mathrm{B}$ (intensity of staining, including: $0=$ no color reaction; $1=$ mild reaction; $2=$ moderate reaction, $3=$ intense reaction) were counted. Final FR scores were then calculated based on the following formula: $F R$ score $=\mathrm{A} \times \mathrm{B}$ [39]. To determine the relationship between probe binding amounts and FR scores, we divided the tissue sections into 29 regions/cross-sections. In each cross-section, we measured its associated NIR intensity and FR score. The linear relationship between each cross-section probe accumulation and FR scores was determined statistically.

\subsection{Co-localization of probes and diseased human tissue}

The probes' ability to detect osteoarthritic tissue was verified using histological methods, which involved determining the locations of probe accumulation and FR expression on human osteoarthritic tissue. Human osteoarthritic tissue incubated with probes (100 $\mu \mathrm{g} / \mathrm{mL}$ for 2 hours) were cryosectioned into two consecutive sections. One section was used for staining FR expression. The second section was used for NIR imaging to visualize the probe distribution. Subsequently, the slide was stained with Safranin $O$ to assess the severity of cartilage tissue degeneration on the surface of the osteoarthritic cartilage. The Safranin O staining was carried out as described earlier [40]. After the staining, the slice was scanned through a pathology slide scanner (PathScan Enabler IV, Meyer Instruments, TX, USA). By merging NIR images and Safranin O images, we would be able to determine whether the probes preferentially accumulated on and diagnosed the location of the degeneration tissue.

\subsection{Statistical analyses}

All the results will be expressed as mean \pm standard error (including FR score on osteoarthritic and healthy cartilage, normalized cell viability, fluorescence of cell targeting and fluorescence on human tissue images). Student t-test was performed to compare the difference between groups. A value of $\mathrm{p} \leq 0.05$ was considered significant. Linear regression analysis was used to determine all calibration curves. The Pearson correlation coefficient ( $\mathrm{R}$ ) was calculated to measure the linear correlation between two variables.

\section{Results}

\subsection{Folate receptor expression on human osteoarthritic tissue}

Using histological analysis, the location of FR expression and macrophage accumulation on osteoarthritic tissue sections was determined. We found that abundant FR expression on the surfaces of osteoarthritic tissue coincided with the accumulation of macrophages (Figure. 1A). These observations supported that most of the macrophages on osteoarthritic tissue expressed FR. Furthermore, by comparison with healthy tissue, there was a substantially higher level of FR expression on osteoarthritic tissue (Figure. 1B). This finding concurred with the FR score results, in which osteoarthritic tissue FR scores were significantly higher than healthy tissue FR scores (Figure. 1B). These results support our overall hypothesis that FR-targeting probes can be employed to diagnose the extent of inflammatory responses on human osteoarthritic cartilage tissue.

\subsection{HA particle synthesis, separation and characterization}

To fabricate FR-targeting probes, we first synthesized HA particles by an emulsion polymerization technique using an AOT/isooctane/ $\mathrm{H}_{2} \mathrm{O}$ emulsion system, while employing DVS as the crosslinker. The fabricated particles exhibited a wide range of particle sizes (Average size $=1161.1 \mathrm{~nm}$, size variation $=89.8 \mathrm{~nm}$ ). To narrow the particle size 
A
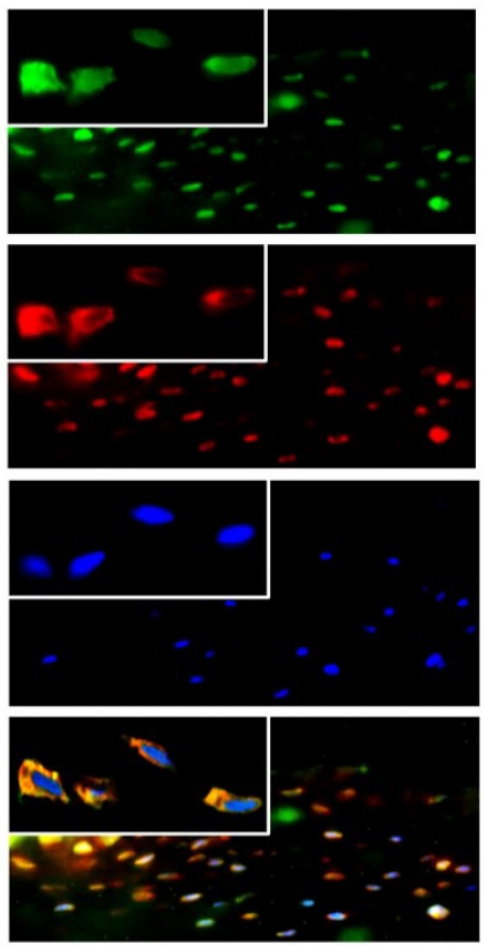

CD68 FR DAPI
B
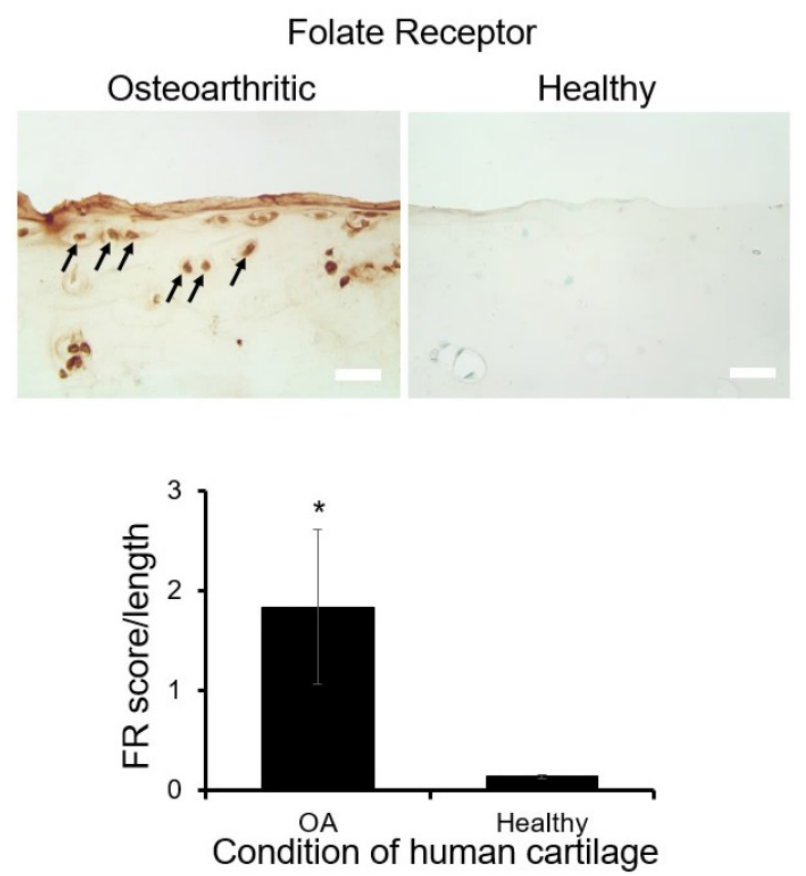

Figure 1. Preliminary histological study on human osteoarthritic tissue (A) Double staining images of folate receptor (FR: Cy3 channel-red) and macrophages (CD68: GFP channel-green, nucleus: DAPI-blue) on human osteoarthritic tissue were taken under 200X and 630X (inserted, oil immersion lens). (B) The expression of FR on osteoarthritic tissue was compared with FR expression on healthy tissue and arrows indicated positive staining result (scale bar: $0.1 \mathrm{~mm}$ ). All the statistical data was presented as mean \pm standard deviation, $n=8$ for $O A$ tissue and $n=3$ for healthy tissue. Student $t$-test was performed to compare the difference between groups (including significance between $F R$ score over length of $O A$ and healthy tissue. A value of ${ }^{*} p \leq 0.05$ was considered significant.

distribution, we applied a differential centrifugation method and collected a small size range of HA particles. DLS determined that the diameter of HA particles was $\sim 490 \mathrm{~nm}$ (Figure. 2A). SEM images of the particles revealed the spherical shape of HA particles although the diameter of the particles reduced to $\sim 200 \mathrm{~nm}$ due to dehydration during the process of sample preparation (insert Figure. 2A). The particles were then conjugated with a NIR dye CF647A. The resultant NIR-labeled HA particles had a maximum absorbance peak at $654 \mathrm{~nm}$ and a maximum emission peak at $680 \mathrm{~nm}$ (Figure. 2B). The conjugation efficiency of CF647A on HA particles was $10.7 \mathrm{nmol} \mathrm{CF647A} \mathrm{per} 1 \mathrm{mg}$ of HA particles.

\subsection{Characterization of FA-conjugated HA probes}

Folate conjugation to HA particles was achieved through a succinimidyl ester-amine reaction between FA-PEG-NH $\mathrm{N}_{2}$ and HA particles. FTIR spectra of FA-HA probes, HA particles and FA confirmed the success of the conjugation process, since the peak of phenyl and pterin rings $\left(1485 \sim 1519 \mathrm{~cm}^{-1}\right)$ [41], a unique marker of FA, appeared on the FTIR spectrum of FA-HA probes (Figure. 2C). Based on the absorbance of FA-HA probes and the calibration curve generated with FA-PEG solution, we determined that the average conjugation efficiency of FA on HA particles was $120 \mathrm{nmol}$ folate per $1 \mathrm{mg}$ of HA particles.

\subsection{Cytotoxicity of HA particles and FA-HA probes}

The cytotoxicity of HA particles and FA-HA probes was determined using human chondrocytes. We found that HA particles had no detectable cytotoxicity up to $1 \mathrm{mg} / \mathrm{mL}$ (Figure. 2D). Similarly, FA-HA probes were found to have no detectable cytotoxicity up to $0.5 \mathrm{mg} / \mathrm{mL}$ (Figure. 2D). Based on these observations, both HA particles and FA-HA probes were used in subsequent studies in media with concentrations $<0.5 \mathrm{mg} / \mathrm{mL}$.

\subsection{FA-HA probes targeting efficiency on activated macrophages}

The ability of FA-HA probes to detect activated macrophages was investigated using both Murine Raw 264.7 macrophage and human THP-1 cell lines. We first examined the interactions between probes and activated THP-1 cells using fluorescence microscopy (Figure. 3A). Cy5 and DAPI images were taken to reveal the location of FA-HA probes and 
A
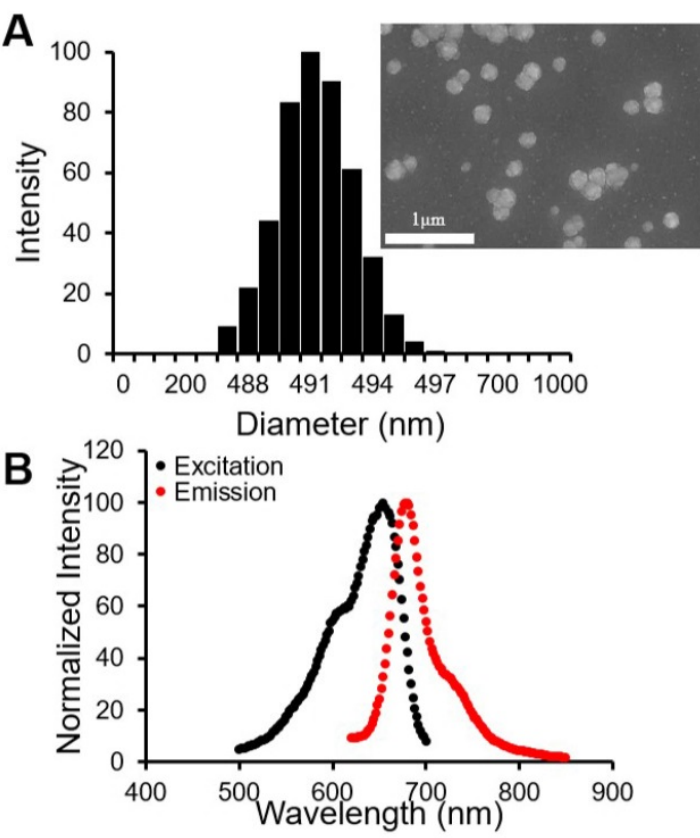

C
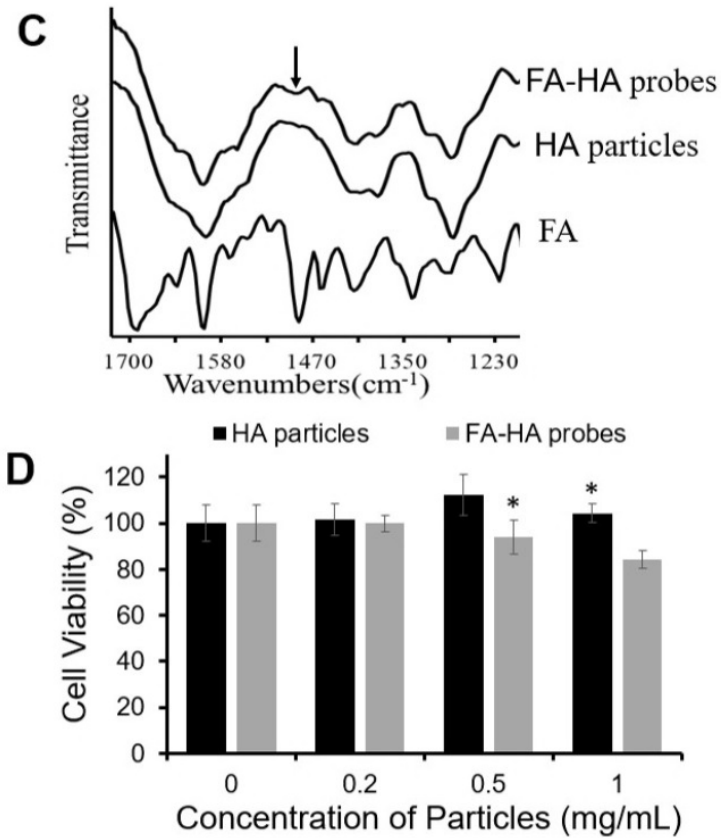

Figure 2. Physical and chemical characterizations of the probes. (A) HA particle size distribution was determined using DLS and particle morphology was observed with SEM (scale bar: $1 \mu \mathrm{m}$ ). (B) The optical properties of the CF647A-labeled FA-HA probes were determined using a microplate reader. (C) Fourier transform infrared spectra of the FA, HA particles and FA-HA probes were employed to confirm the conjugation process. The arrow notes the peak of the phenyl and pterin rings (1485 1519 $\left.\mathrm{cm}^{-1}\right)$. (D) Chondrocyte cytotoxicity study was carried out using HA particles and FA-HA probes. All the statistical data was presented as mean \pm standard deviation, $\mathrm{n}=3$ for each group. Student $\mathrm{t}$-test was performed to compare cytotoxicity of different probe concentrations with the control group. $* \mathrm{P} \leq 0.05$ : Significance vs. the same materials (either HA particles or FA-HA probes).

macrophages, respectively. By overlaying both Cy5 and DAPI images, we clearly saw a large number of FA-HA probes on the surfaces of activated macrophages, which would directly support the targeting process. By measuring cell-associated fluorescent intensities at different time points (15 and 30 minutes), we found that FA-HA probes had a significant higher specificity to activated macrophages ( 10X) than to naïve cells (Figure. 3B). Additionally, the amounts of probes accumulated on activated macrophages in 15 minutes are only slightly less than those in 30 minutes (Figure. 3B). To determine the role of FA on probes in targeting activated macrophages, a competition-binding test was performed in which free folate molecules were incubated with activated macrophages prior to the addition of FA-HA probes. As expected, prior incubation of free FA $(18 \mu \mathrm{M})$ significantly reduce $(\sim 67 \%) \quad$ FA-HA probe affinity to activated macrophages. These results support that probe accumulation on activated macrophages was mediated by the interaction between FA on probe and FR on inflammatory cells (Figure. 3C).

To explore the idea about whether probes could be used to quantify the numbers of activated macrophages, different numbers of activated Murine Raw 264.7 macrophages (treated with LPS) were incubated with FA-HA probes and control particles. After incubation for 30 minutes, we then assessed the probes' binding affinity by measuring the cell-associated fluorescent intensities. In agreement with earlier results, we found that there was a strong linear relationship between the number of activated macrophages and FA-HA probe associated fluorescent intensity $(\mathrm{R}=0.993)$ (Figure. 3D). The FA-HA probes' binding affinity to activated macrophages was calculated to be $7.00 \pm 1.91 \mathrm{ng} / \mathrm{cell}$. On the other hand, there was only a small amount of the control particles associated with activated macrophages. These results agreed with our hypothesis that FA-HA probes can be used to detect and quantify activated macrophages.

\subsection{Imaging efficiency on human osteoarthritic cartilage}

Using human osteoarthritic cartilage tissue, we then investigated the ability of FA-HA probes to detect activated macrophages on human osteoarthritic cartilage explants ex vivo. Specifically, osteoarthritic tissue was first incubated with different concentrations (100 vs $20 \mu \mathrm{g} / \mathrm{mL}$ ) of FA-HA probes and HA particles for different periods of time $(30,45$, 75, 105 and 135 minutes) and then imaged using an NIR imager (Figure. 4A). Interestingly, shortly after incubation with FA-HA probes, we saw an uneven fluorescent signal distribution on osteoarthritic tissue. Based on the average fluorescent intensity acquired from the randomly picked ROI, we find that FA-HA probes reach their peak targeting efficiency as early as 30 minutes (Figure. 4B). In general, the average 
A

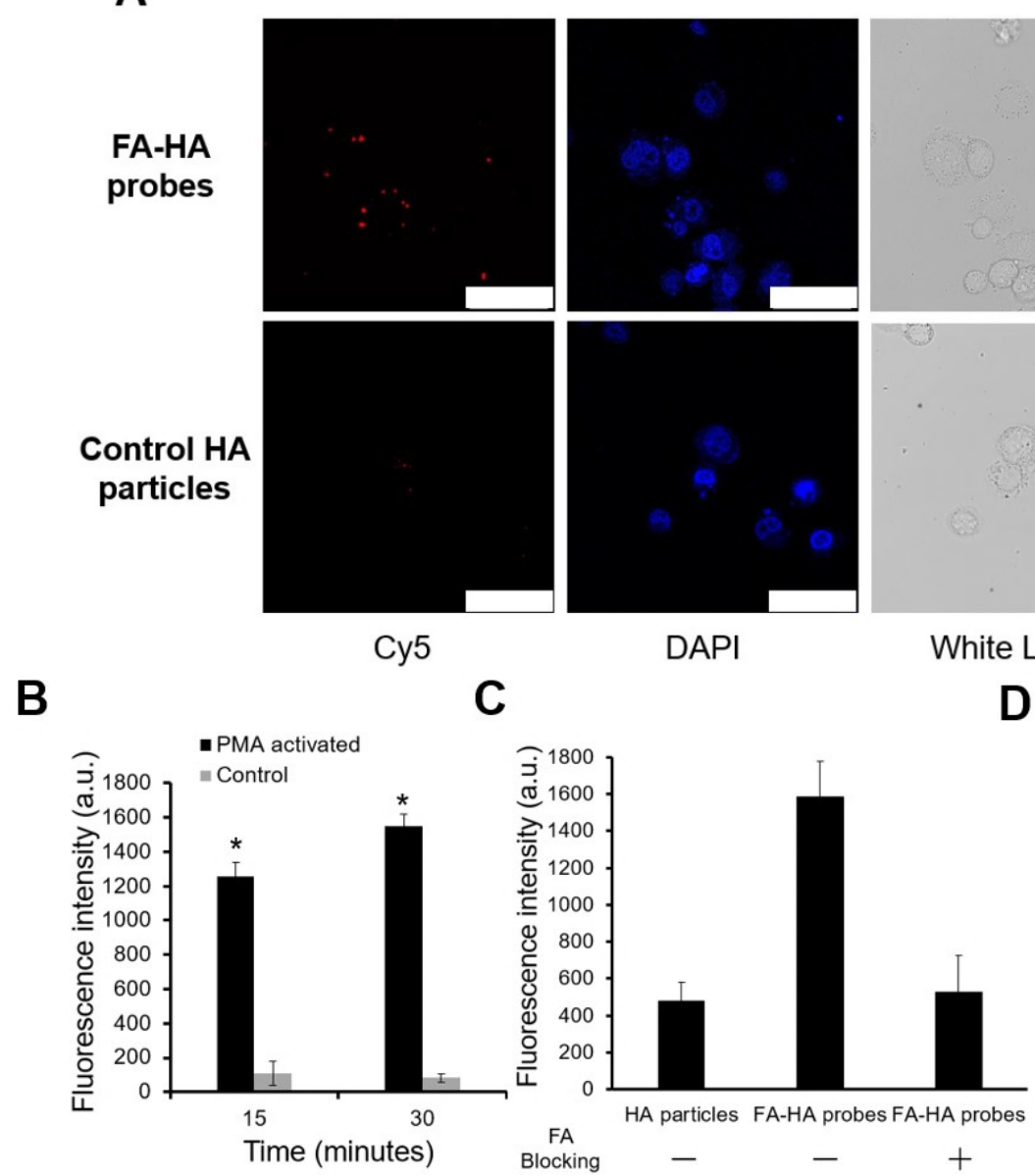

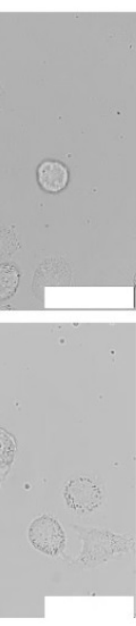

White Light

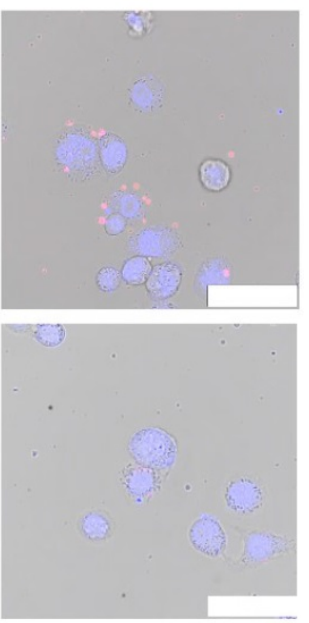

Overlay

D

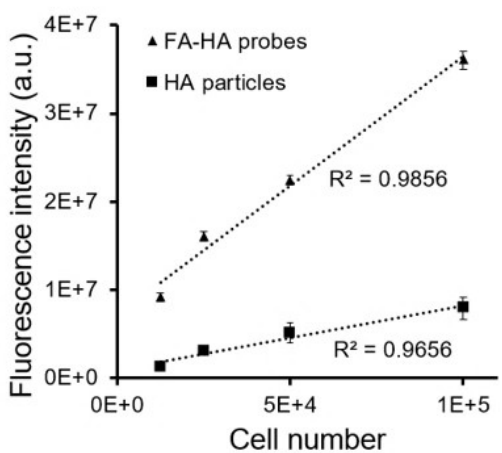

Figure 3. In vitro evaluation of the FA-HA probe's ability to target both activated human THP-1 cells (Figure 3A\&B) and Murine Raw 264.7 macrophages (Figure 3C). (A) Fluorescent and white light images of activated macrophages treated with FA-HA probes and control HA particles at different channels - Cy5 channel (probes/particles), DAPI channel (macrophages), white light channel and overlay channel (scale bar: $50 \mu \mathrm{m}$ ). (B) Fluorescent intensities of PMA activated macrophages and naïe macrophages after incubation with FA-HA probes for 15 and 30 minutes. (C) Fluorescent intensities of HA particles or FA-HA probes on activated macrophages with or without the pre-treatment of free FA $(18 \mu \mathrm{M})$ for 30 minutes. (D) The relationship between the number of activated Raw 264.7 macrophages and fluorescent intensities of cell-bound FA-HA probes/HA particles. All the statistical data was presented as mean \pm standard deviation, $n=3$ for all groups. Pearson correlation coefficients were calculated between cell numbers and cell associated fluorescent intensities. A value of * $\mathrm{p} \leq 0.05$ was considered significant.

intensity of the $100 \mu \mathrm{g} / \mathrm{mL}$ group was about $2.5 \mathrm{X}$ higher than the intensity of the $20 \mu \mathrm{g} / \mathrm{mL}$ group. Moreover, the amount of FA-HA probes associated with human OA cartilage was about 2.6 and 2.3 folds more than that of control HA particles at the concentrations of 100 and $20 \mu \mathrm{g} / \mathrm{mL}$, respectively. These findings supported that a higher administration dose contributed to a better imaging capability in vitro and the probes had a significant better targeting efficiency than control HA particles.

\subsection{Quantification of folate receptor expression on human osteoarthritic tissue.}

$\mathrm{OA}$ is associated with a varying degree of inflammatory responses at different areas of cartilage tissue. Under white light, osteoarthritic cartilage tissue showed slightly opaque, rough and yellowed surfaces (Figure 5A). In addition, the extent of inflammatory responses on different areas of cartilage tissue could not be easily identified by naked eyes.
However, using FA-HA probes and NIR imaging, we could easily identify the area of extensive inflammatory responses on human cartilage tissue (Figure 5B). To assess the relationship between probe binding amounts and FR scores on cartilage tissue, we divided each tissue sections into 29 regions across the whole section. For each region, we determined the intensities of tissue associated probes (via NIR imaging) (Figure 5B) and the extent of FR expression (via FR scores) (Figure 5C). Using statistical analysis, we found a linear relationship between the NIR signal intensities and FR scores (Figure. 5D). Through the regression analysis, probe fluorescent intensity was found to have a strong correlation with the FR number (Mean probe intensity $=104.25 \times$ FR number -37.066, $\mathrm{R}=0.933)$. The statistical results of this experiment supported our hypothesis that FA-HA probes can be used to assess the severity of human OA cartilage. 

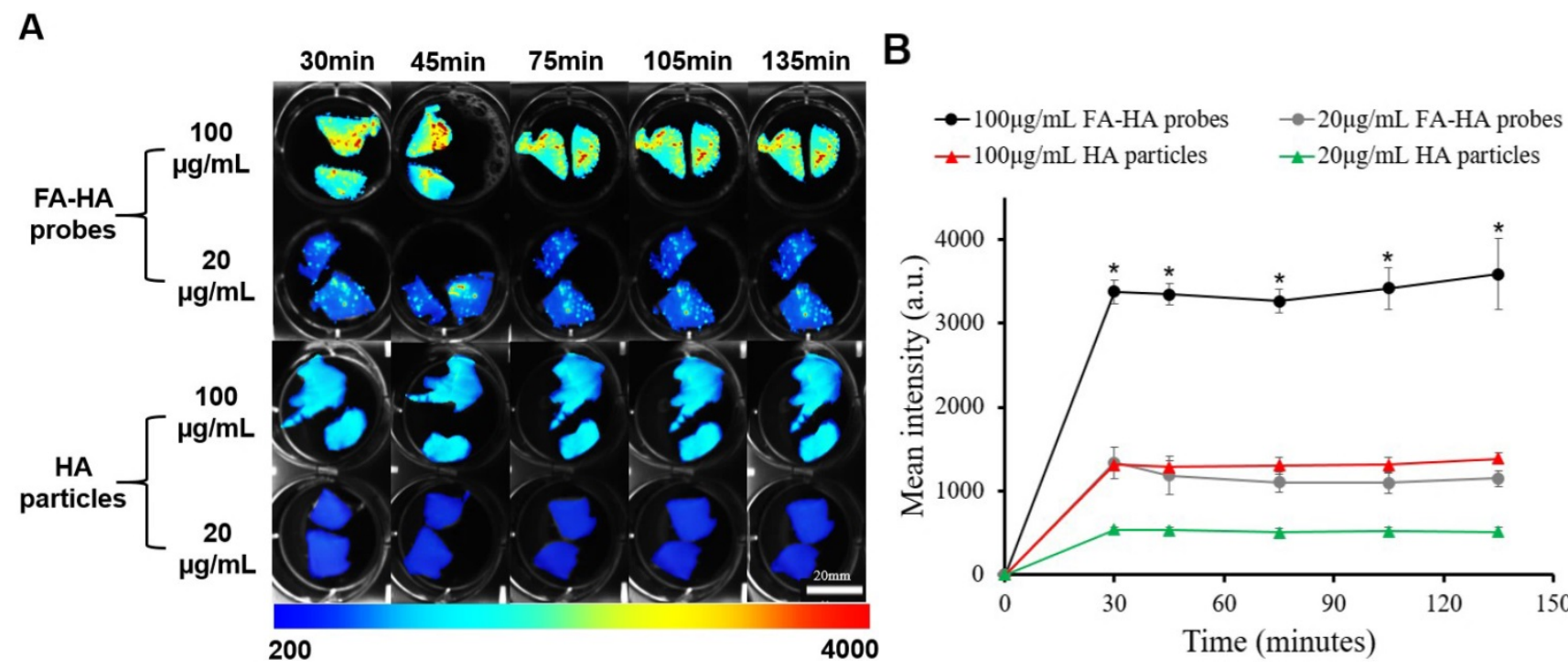

Figure 4. The ability of FA-HA probes to diagnose injured cartilage was evaluated using human osteoarthritic tissue in vitro. (A) Time and dose dependent fluorescent images of osteoarthritic human tissue co-cultured with different concentrations of FA-HA probes and HA particles (as control) (scale bar: 20mm). (B) The fluorescent intensities of all tissue incubated with different concentrations $(20$ and $100 \mu \mathrm{g} / \mathrm{ml})$ of FA-HA probes and HA particle controls for different periods of time (up to 140 minutes) were calculated and compared. $n=6$ for all groups. The background fluorescence intensity of the HA particle control incubated tissue was $360 \pm 17$. A value of $* p \leq 0.05$ was considered be significant.

A

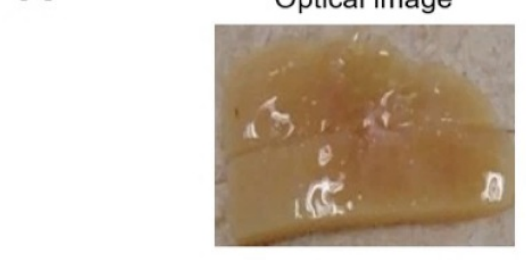

B

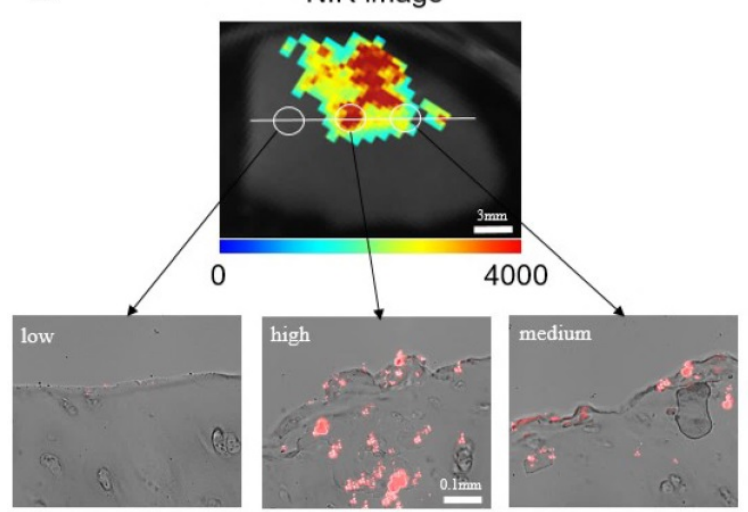

C

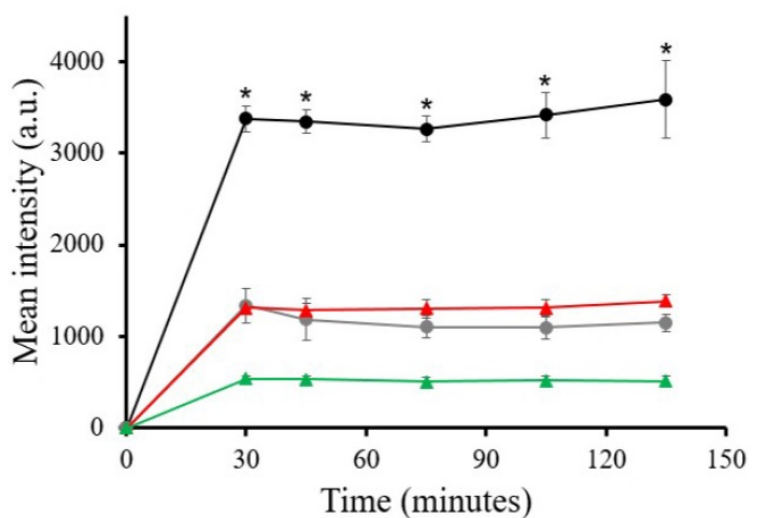

igure 5. Relationship between fluorescent imaging and histological analysis results. (A) Optical image of human osteoarthritic tissue before OCT embedding. (B) Top panel: NIR fluorescent image of human osteoarthritic tissue taken after being incubated with FA-HA probes for 30 minutes. Bottom panel: probe incubated tissue was divided into 29 sections and then imaged using confocal laser scanning microscopy. Representative images of low, medium and high amounts of probe accumulation on tissue. (C) Top panel: representative images of FR IHC stained tissue with low, medium and high folate receptor scores. Images were taken under $200 X$ microscope. Bottom panel: whole tissue image was taken using PathScan. (D) The linear relationship between tissue associated fluorescent intensities in each region and corresponding folate receptor scores on human osteoarthritic tissue were determined statistically with a Pearson correlation coefficient of 0.933 .

\subsection{Co-localization of FA-HA probes and FR expression and cartilage tissue degeneration}

We further determined the FA-HA probes' ability for OA diagnosis by using confocal laser scanning microscopy and histological analysis to examine the probe distribution and degenerative cartilage tissue, respectively. As present in the stitched images, the probe distribution can be visualized clearly on the surface of the osteoarthritic cartilage sample (Figure. 6A). To determine the extent of cartilage degeneration, we used both FR IHC and Safranin $\mathrm{O}$ staining. The FR IHC stain imaging revealed a heterogeneous surface structure, indicating the degenerative nature of the OA tissue (Figure. 6B). Safranin $\mathrm{O}$ staining has been widely used to quantify proteoglycan content and to reflect the extent of cartilage degeneration. As anticipated, the Safranin O 

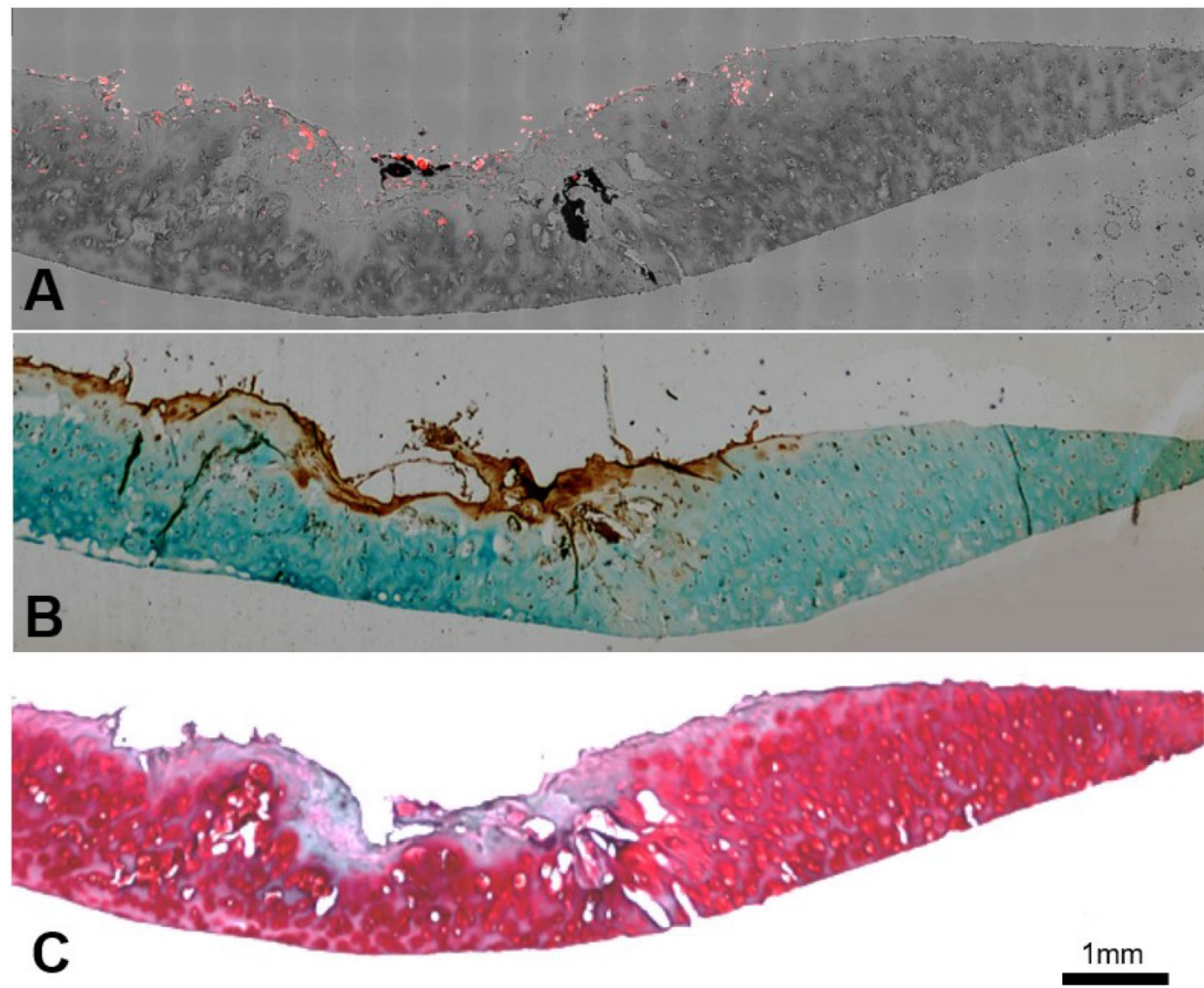

Figure 6. Co-localization of probes and cartilage tissue degeneration on human osteoarthritic explants were carried out using both confocal imaging and histological analysis. (A) Stitching image of FA-HA probe distribution on exposed tissue was taken using a Leica confocal laser-scanning microscope. (B) Scanning image of FR IHC staining on adjacent tissue section was taken using PathScan. (C) Scanning image of Safranin O staining on the identical tissue section (as in Figure 6A) was taken using PathScan.

staining revealed the location and extent of cartilage degeneration (Figure. 6C). Impressively, the highest fluorescent intensity was located exactly at the most degenerated area, which means the probes were able to indicate the area of degenerative cartilage tissue through a specific targeting process.

\section{Discussion}

In the present study, FA-conjugated HA probes were fabricated and investigated for their ability to diagnose inflammatory responses on human osteoarthritic cartilage explants. Our results support that FA-HA probes can be used to detect activated macrophages via NIR imaging. In addition, probe-associated fluorescent intensities can be measured to reflect the number of activated macrophages in culture. By applying FA-HA probes $(100 \mu \mathrm{g} / \mathrm{mL})$ on cartilage tissue, we can visualize the extent of inflammatory responses on cartilage tissue within 30 minutes in the presence of free probes. Even though Osteoarthritis Research Society International (OARSI) histological scoring has been widely used to determine the overall knee joint damage, OARSI scores can only reflect an average cartilage tissue injury and cannot be used to identify the areas of injured cartilage. We believe that the FA-HA probes can be used to identify localized cartilage injury by taking advantage of an intra-articular imaging technique established earlier [42].

The results of this work supports that FR can be used as a targeting ligand for $\mathrm{OA}$ diagnosis in humans. It should be noted that several different probes with different targeting ligands have been developed for in vivo OA diagnosis recently. Firstly, cathepsin B, an extracellular cysteine protease, was used as a marker of OA. Specifically, cathepsin B sensitive NIR probes were fabricated and then investigated for early OA diagnosis [43]. Secondly, fluorescence resonance energy transfer MMP-13 fluorogenic probes were fabricated and investigated for in vivo OA detection [44]. Thirdly, ApoPep-1 (CQRPPR), a peptide that is able to bind to apoptotic and necrotic cells, was tested for its ability to detect OA in vivo via its binding to apoptotic chondrocytes [45]. 
Different imaging modalities have been investigated for OA diagnosis with different advantages and disadvantages. For example, an investigational folate receptor-targeting companion imaging agent, 99mTc-folate (Etarfolatide), has recently been used to assay the participation of activated macrophages in a substantial proportion of human osteoarthritic knees using SPECT-CT [46]. However, the imaging method is invasive, causes negative side effects due to the imaging agent [47] and the bioavailability provided by intravaneous injection is low for articular cartilage due to the avascular structure, which leads to insufficient imaging information for diagnosis [48]. Conversely, our probe is fabricated with HA, which has been approved by the United States Food and Drug Administration for intra-articular injection since 2001 [49, 50]. Despite the improved penetration depth of NIR imaging [51], it is possible that the accumulation of FA-HA probes on cartilage tissue cannot be detected non-invasively. In that case, a fluorescence arthroscope may be used to image the probe accumulation on cartialge tissue in situ, which has been documented recently [52].

HA is selected for this application based on the following advantages: first, HA has been used in the form of particles and tissue scaffolds for enhancing cartilage tissue repair and regeneration [53]; Second, studies have shown that $\mathrm{HA}$ is able to mediate chondrocyte proliferation and matrix synthesis in a cartilage microenvironment through the CD44-HA pathway [54]; and finally, HA may diminish immune responses by reducing the motility of lymphocytes [55], which would lead to inhibition of PMN leukocyte migration [56] and neutrophil aggregation and adhesion [57]. These unique characteristics may permit the further development of FA-HA probes into a treatment method that induces chondrogenic tissue regeneration and healing in osteoarthritic cartilage tissue. It should be noted that many other biocompatible, water soluble and biodegradable polymers have been developed as in vivo imaging probes [58]. For example, Poly(ethylene glycol) [59], Poly (L-glutamic acid) [60] and N-(2-Hydroxypropyl) methacrylamide [61] with various functional groups have been used to fabricate probes with different targeting and therapeutic moieties. It is possible the FR-targeting probes can be made using different polymer carriers. However, further studies are needed to determine the potential effects of polymer types on probe-cell interactions and affinity.

\section{Conclusion}

FA-targeting and NIR-labeled HA probes have been successfully designed to target FR-upregulated cells in culture and on human osteoarthritic tissue explants. These probes were characterized to be spherical, nanoscale and non-cytotoxic; in addition, they exhibited a strong targeting efficiency on FR upregulated macrophages. Furthermore, by adding the probes in the solution, we can not only visualize the area but also the extent of inflammatory and degenerative cartilage tissue in 30 minutes ex vivo. Our results support that this imaging probe has a tremendous potential to be used as a novel diagnostic method to evaluate OA in a clinical setting.

\section{Abbreviations}

OA: osteoarthritis; HA: hyaluronic acid; FA: folic acid; FR: Folate receptor, MRI: magnetic resonance imaging; TNF-a: tumor necrosis factor alpha; IL-1 $\beta$ : Interleukin 1 beta; NIR: near infrared; DVS: Divinyl sulfone; AOT: dioctyl sulfosuccinate sodium salt; NHS: N-hydroxysuccinimide; EDC: 1-Ethyl-3-(3dimethylaminopropyl) carbodiimide; PBS: phosphate buffered saline; FTIR: fourier-transform infrared spectroscopy; FBS: fetal bovine serum; PMA: phorbol 12-myristate 13-acetate; LPS: lipopolysaccharide; ROI: Region of Interest; IHC: immunohistochemistry; DLS: dynamic light scattering; SEM: scanning electron microscope.

\section{Acknowledgements}

This work was partially supported by a Research \& Scholarship Excellence Gift and a Translational Research Award No. W81XWH-14-1-0459 from the Defense Health Program through the Department of Defense Peer Reviewed Orthopaedic Research Program. Opinions, interpretations, conclusions and recommendations were those of the authors and are not necessarily endorsed by the Department of Defense.

\section{Competing Interests}

The authors have declared that no competing interest exists.

\section{References}

[1] Kotlarz H, Gunnarsson CL, Fang H, Rizzo JA. Insurer and out-of-pocket costs of osteoarthritis in the US: evidence from national survey data. Arthritis Rheum. 2009;60:3546-53.

[2] Luo X, Pietrobon R, Sun SX, Liu GG, Hey L. Estimates and patterns of direct health care expenditures among individuals with back pain in the United States. Spine. 2004;29:79-86.

[3] Chu CR, Williams AA, Coyle CH, Bowers ME. Early diagnosis to enable early treatment of pre-osteoarthritis. Arthritis Res Ther. 2012;14:212.

[4] Eckstein F, Wirth W, Nevitt MC. Recent advances in osteoarthritis imaging - the osteoarthritis initiative. Nat Rev Rheumatol. 2012;8:622-30.

[5] Ding C, Zhang Y, Hunter D. Use of imaging techniques to predict progression in osteoarthritis. Curr Opin Rheumatol. 2013;25:127-35.

[6] Fernandez-Madrid F, Karvonen RL, Teitge RA, Miller PR, An T, Negendank WG. Synovial thickening detected by MR imaging in osteoarthritis of the knee confirmed by biopsy as synovitis. Magn Reson Imaging. 1995;13:177-83.

[7] Guermazi A, Roemer FW, Burstein D, Hayashi D. Why radiography should no longer be considered a surrogate outcome measure for 
longitudinal assessment of cartilage in knee osteoarthritis. Arthritis Res Ther. 2011;13:247.

[8] Kraus VB. Editorial [Hot Topic: Waiting for Action on the Osteoarthritis Front (Guest Editors: Virginia Byers Kraus and Thomas Aigner)]. Curr Drug Targets. 2010;11:518-20.

[9] Kandahari AM, Yang X, Dighe AS, Pan D, Cui Q. Recognition of immune response for the early diagnosis and treatment of osteoarthritis. J Immunol Res. 2015;2015:1-13.

[10] de Lange-Brokaar B, Ioan-Facsinay A, Van Osch G, Zuurmond A-M, Schoones J, Toes R, et al. Synovial inflammation, immune cells and their cytokines in osteoarthritis: a review. Osteoarthritis Cartilage. 2012;20:1484-99.

[11] Bondeson J, Blom AB, Wainwright S, Hughes C, Caterson B, van den Berg WB. The role of synovial macrophages and macrophage-produced mediators in driving inflammatory and destructive responses in osteoarthritis. Arthritis Rheum. 2010;62:647-57.

[12] Bondeson J, Wainwright SD, Lauder S, Amos N, Hughes CE. The role of synovial macrophages and macrophage-produced cytokines in driving aggrecanases, matrix metalloproteinases, and other destructive and inflammatory responses in osteoarthritis. Arthritis Res Ther. 2006;8:R187.

[13] Yang X, Chordia MD, Du X, Graves JL, Zhang Y, Park YS, et al. Targeting formyl peptide receptor 1 of activated macrophages to monitor inflammation of experimental osteoarthritis in rat. J Orthop Res. 2016;34:1529-38.

[14] Pessler F, Chen L, Dai L, Gomez-Vaquero C, Diaz-Torne C, Paessler M, et al. A histomorphometric analysis of synovial biopsies from individuals with Gulf War Veterans' Illness and joint pain compared to normal and osteoarthritis synovium. Clin Rheumatol. 2008;27:1127-34.

[15] Blom AB, van Lent PL, Holthuysen AE, van der Kraan PM, Roth J, van Rooijen N, et al. Synovial lining macrophages mediate osteophyte formation during experimental osteoarthritis. Osteoarthritis Cartilage. 2004;12:627-35.

[16] Antony AC. Folate receptors. Annu Rev Nutr. 1996;16:501-21.

[17] Paulos CM, Varghese B, Widmer WR, Breur GJ, Vlashi E, Low PS. Folate-targeted immunotherapy effectively treats established adjuvant and collagen-induced arthritis. Arthritis Res Ther. 2006;8:R77.

[18] Low PS, Henne WA, Doorneweerd DD. Discovery and development of folic-acid-based receptor targeting for imaging and therapy of cancer and inflammatory diseases. Acc Chem Res. 2008;41:120-9.

[19] Xia W, Hilgenbrink AR, Matteson EL, Lockwood MB, Cheng JX, Low PS. A functional folate receptor is induced during macrophage activation and can be used to target drugs to activated macrophages. Blood. 2009;113:438-46.

[20] Nakashima-Matsushita N, Homma T, Yu S, Matsuda T, Sunahara N, Nakamura T, et al. Selective expression of folate receptor beta and its possible role in methotrexate transport in synovial macrophages from patients with rheumatoid arthritis. Arthritis Rheum. 1999;42:1609-16.

[21] Chen W-T, Mahmood U, Weissleder R, Tung C-H. Arthritis imaging using a near-infrared fluorescence folate-targeted probe. Arthritis Res Ther. 2005;7:R310.

[22] Piscaer TM, Muller C, Mindt TL, Lubberts E, Verhaar JA, Krenning EP, et al. Imaging of activated macrophages in experimental osteoarthritis using folate-targeted animal single-photon-emission computed tomography/computed tomography. Arthritis Rheum. 2011;63:1898-907.

[23] Turk MJ, Breur GJ, Widmer WR, Paulos CM, Xu LC, Grote LA, et al. Folate-targeted imaging of activated macrophages in rats with adjuvant-induced arthritis. Arthritis Rheum. 2002;46:1947-55.

[24] Hansch A, Frey O, Sauner D, Hilger I, Haas M, Malich A, et al. In vivo imaging of experimental arthritis with near-infrared fluorescence. Arthritis Rheum. 2004;50:961-7.

[25] Kim H, Jeong H, Han S, Beack S, Hwang BW, Shin M, et al. Hyaluronate and its derivatives for customized biomedical applications. Biomaterials. 2017;123:155-71.

[26] Dosio F, Arpicco S, Stella B, Fattal E. Hyaluronic acid for anticancer drug and nucleic acid delivery. Adv Drug Del Rev. 2016;97:204-36.

[27] Tripodo G, Trapani A, Torre ML, Giammona G, Trapani G, Mandracchia D. Hyaluronic acid and its derivatives in drug delivery and imaging: recent advances and challenges. Eur J Pharm Biopharm. 2015;97:400-16.

[28] Xu X, Jha AK, Duncan RL, Jia X. Heparin-decorated, hyaluronic acid-based hydrogel particles for the controlled release of bone morphogenetic protein 2. Acta Biomater. 2011;7:3050-9.

[29] Yoon HY, Koo H, Choi KY, Lee SJ, Kim K, Kwon IC, et al. Tumor-targeting hyaluronic acid nanoparticles for photodynamic imaging and therapy. Biomaterials. 2012;33:3980-9.

[30] Zhang J, Rana S, Srivastava RS, Misra RD. On the chemical synthesis and drug delivery response of folate receptor-activated, polyethylene glycol-functionalized magnetite nanoparticles. Acta Biomater. 2008;4:40-8.
[31] Yap WT, Song WK, Chauhan N, Scalise PN, Agarwal R, Shea LD. Quantification of particle-conjugated or-encapsulated peptides on interfering reagent backgrounds. Biotechniques. 2014;57:39-44.

[32] Fasman GD. Practical handbook of biochemistry and molecular biology. Florida, USA: CRC press; 1989.

[33] Huang Y, Zhou J, Hakamivala A, Wu J, Hong Y, Borrelli J, et al. An optical probe for detecting chondrocyte apoptosis in response to mechanical injury. Sci Rep. 2017;7:10906.

[34] Zhou J, Tsai YT, Weng H, Baker DW, Tang L. Real time monitoring of biomaterial-mediated inflammatory responses via macrophage-targeting NIR nanoprobes. Biomaterials. 2011;32:9383-90.

[35] Monteiro-Riviere N, Inman A, Zhang L. Limitations and relative utility of screening assays to assess engineered nanoparticle toxicity in a human cell line. Toxicol Appl Pharmacol. 2009;234:222-35.

[36] Hattori Y, Sakaguchi M, Maitani Y. Folate-linked lipid-based nanoparticles deliver a NFKB decoy into activated murine macrophage-like RAW264. 7 cells. Biol Pharm Bull. 2006;29:1516-20.

[37] Zhou S, Thornhill TS, Meng F, Xie L, Wright J, Glowacki J. Influence of osteoarthritis grade on molecular signature of human cartilage. J Orth Res. 2016;34:454-62.

[38] Peng Z, Zhou J, Dacy A, Zhao D, Kearney V, Zhou W, et al. Design of a portable imager for near-infrared visualization of cutaneous wounds. J Biomed Opt. 2017;22:016010-

[39] Fedchenko N, Reifenrath J. Different approaches for interpretation and reporting of immunohistochemistry analysis results in the bone tissue-a review. Diagn Pathol. 2014;9:221.

[40] Schmitz N, Laverty S, Kraus V, Aigner T. Basic methods in histopathology of joint tissues. Osteoarthritis Cartilage. 2010;18:S113-S6.

[41] Mohammed EMKA-D. Qualitative and Quantitative Determination of Folic acid in Tablets by FTIR Spectroscopy. IJAPBC. 2014;3:773-80.

[42] Ike RW. Diagnostic arthroscopy. Baillieres Clin Rheumatol. 1996;10:495-517.

[43] Lai W-FT, Chang C-H, Tang Y, Bronson R, Tung C-H. Early diagnosis of osteoarthritis using cathepsin B sensitive near-infrared fluorescent probes. Osteoarthritis Cartilage. 2004;12:239-44.

[44] Ryu JH, Lee A, Na JH, Lee S, Ahn HJ, Park JW, et al. Optimization of matrix metalloproteinase fluorogenic probes for osteoarthritis imaging. Amino Acids. 2011;41:1113-22.

[45] Che X, Chi L, Park CY, Cho G-H, Park N, Kim S-G, et al. A novel method to detect articular chondrocyte death during early stages of osteoarthritis using a non-invasive ApoPep-1 probe. Arthritis Res Ther. 2015;17:309.

[46] Kraus VB, McDaniel G, Huebner JL, Stabler TV, Pieper CF, Shipes SW, et al. Direct in vivo evidence of activated macrophages in human osteoarthritis. Osteoarthritis Cartilage. 2016;24:1613-21.

[47] Zolle I. Technetium-99m pharmaceuticals. Vienna, Austria: Springer; 2007.

[48] Sophia Fox AJ, Bedi A, Rodeo SA. The basic science of articular cartilage: structure, composition, and function. Sports health. 2009;1:461-8.

[49] Acc Chem ResAltman R, Manjoo A, Fierlinger A, Niazi F, Nicholls M. The mechanism of action for hyaluronic acid treatment in the osteoarthritic knee: a systematic review. BMC Musculoskel Disord. 2015;16:321.

[50] Printz JO, Lee JJ, Knesek M, Urquhart AG. Conflict of interest in the assessment of hyaluronic acid injections for osteoarthritis of the knee: an updated systematic review. J Arthroplasty. 2013;28:30-3. e1.

[51] Weissleder R, Ntziachristos V. Shedding light onto live molecular targets. Nat Med. 2003;9:123-8.

[52] Nguyen DT, van Horssen P, Derriks H, van de Giessen M, van Leeuwen T. Autofluorescence imaging for improved visualization of joint structures during arthroscopic surgery. J Exp Orthop. 2017;4:19.

[53] Collins MN, Birkinshaw C. Hyaluronic acid based scaffolds for tissue engineering - A review. Carbohydr Polym. 2013;92:1262-79.

[54] Ishida O, Tanaka Y, Morimoto I, Takigawa M, Eto S. Chondrocytes are regulated by cellular adhesion through CD44 and hyaluronic acid pathway. J Bone Miner Res. 1997;12:1657-63.

[55] Balazs E, Darzynkiewicz Z. The effect of hyaluronic acid on fibroblasts, mononuclear phagocytes and lymphocytes. Biology and fibroblasts. 1973;66:237-52.

[56] Partsch G, Schwarzer C, Neumüller J, Dunky A, Petera P, Bröll H, et al. Modulation of the migration and chemotaxis of PMN cells by hyaluronic acid. Z Rheumatol. 1989;48:123-8.

[57] Forrester JV, Lackie J. Effect of hyaluronic acid on neutrophil adhesion. J Cell Sci. 1981;50:329-44

[58] Zhang Y, Yang J. Design strategies for fluorescent biodegradable polymeric biomaterials. J Mater Chem B. 2013;1:132-48.

[59] Okuda T, Kobayashi Y, Yanamoto S, Okamoto H. PEG conjugation of a near-infrared fluorescent probe for noninvasive dual imaging of lung deposition and gene expression by pulmonary gene delivery. J Drug Targeting. 2012;20:801-12. 
[60] Melancon MP, Wang W, Wang Y, Shao R, Ji X, Gelovani JG, et al. A novel method for imaging in vivo degradation of poly (L-glutamic acid), a biodegradable drug carrier. Pharm Res. 2007;24:1217-24.

[61] Zhang Y, Guo C, Li S, Luo K, Hu J, Gu Z. The Potential of Poly [N-(2-hydroxypropyl) methacrylamide] via Reversible Addition-Fragmentation Chain Transfer Polymerization as Safe Nanocarrier. J Nanosci Nanotechnol. 2016;16:5746-54. 